\title{
EDITORIAL
}

\section{Anti-interleukin-13 antibody therapy for asthma: one step closer}

\author{
Jonathan Corren*,\#
}

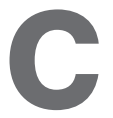
urrent guidelines for the treatment of asthma recommend inhaled corticosteroids for all patients with persistent asthma. Despite the increasing use of these drugs, asthma remains poorly controlled in a small subset of individuals who do not respond fully to existing therapies. The medical needs of these patients have prompted a search for new medications that inhibit specific molecular targets thought to play key roles in asthma pathogenesis.

Interleukin (IL)-13 is a cytokine that represents a potential critical factor in the development and persistence of asthma. Originally discovered in 1993, IL-13 was identified by molecular cloning in activated human T-lymphocytes [1]. Subsequent in vitro studies have demonstrated that IL-13 has a broad range of activities, including effects upon lymphocytes (switching of immunoglobulin isotype synthesis by B-cells from immunoglobulin (Ig)M to IgE [2]), eosinophils (increased adhesion to the vascular endothelium [3] and augmentation of cell survival [4]), mast cells (proliferation and activation [5]), epithelium (increased epithelial permeability [6], and induction of goblet cell differentiation and growth [7]), fibroblasts (transformation into myofibroblasts and production of collagen [8]) and smooth muscle (diminished relaxation in response to $\beta$-agonists [9] and augmentation of contractility in response to acetylcholine [10]).

In tandem with the above in vitro experiments, the potential role of IL-13 in airways disease has been investigated in animal studies. Using a murine model of allergic asthma, neutralisation of IL-13 led to reversal of airway hyperresponsiveness and inflammation, while administration of IL-13 was sufficient to induce the pathophysiological features of asthma independently of $\operatorname{IgE}$ and eosinophils [11, 12]. These observations from an animal model have been shown to have possible relevance to asthma in humans, as IL-13 has been identified to be upregulated in the blood [13], sputum [14], bronchoalveolar lavage fluid [15] and bronchial mucosa [14] of asthmatics compared with nonasthmatic individuals.

The recent development of monoclonal antibodies directed against IL-13 is now providing clinical investigators with opportunities to better define the relevant effects of IL-13 in asthma and to determine whether IL-13 inhibition is effective in

*Dept of Medicine, University of California, and ${ }^{\#}$ Allergy Medical Clinic, Los Angeles, CA, USA.

CORRESPONDENCE: J. Corren, Dept of Medicine, University of California, Los Angeles and Allergy Medical Clinic, 10780 Santa Monica Blvd, \#280, Los Angeles, CA 90025, USA. E-mail: jcorren@ucla.edu patients refractory to existing therapies. As we embark on clinical trials of these agents, a number of important questions arise. First, as IL-4 has been shown to share most activities with IL-13, and has also been identified in the sputum and bronchial tissue of patients with asthma [13], can an agent specifically aimed at IL-13 alone be effective? In the murine model of allergic airway disease, IL-13 has been shown to be more important than IL-4 for induction of airway hyperresponsiveness and chronic remodelling changes, including smooth muscle hyperplasia and subepithelial fibrosis [11, 12]. These findings may, in part, be due to considerably higher pulmonary concentrations of IL-13 than IL-4 in sensitised mice [16]. This phenomenon appears to be true in human asthma as well, as IL-13-producing cells significantly outnumber those making IL-4 [17]. Therefore, as IL-13 is probably the predominant cytokine of the two, therapies directed towards specific IL-13 antagonism may have significant therapeutic effects. Secondly, given the increasing evidence of the pathophysiological heterogeneity of asthma, are there clinical, immunological or biochemical characteristics capable of predicting a positive response to IL-13 inhibition? While the answer to this question is only partly certain, emerging data have provided us with a number of laboratory tests that correlate significantly with airway-derived IL-13 and T-helper cell (Th) type 2 inflammation. Both total serum IgE and blood eosinophils are established markers of Th2 inflammation and, therefore, might be useful as predictors of anti-IL-13 responsiveness [18]. Recently, a number of serum proteins produced by the airway epithelium, including periostin, chloride channel regulator 1 and serpin peptidase inhibitor, have all been shown to be elevated in asthmatics who have increased levels of pulmonary IL-13 and a Th2 phenotype [18]. In addition, IL-13 has been shown to regulate nitric oxide synthase and, thereby, directly control the quantities of nitric oxide that are produced and exhaled from the lungs [19]. One or more of these parameters may, therefore, serve as surrogate markers of increased IL-13 activity in the airways and help in identifying asthmatics who are most likely to benefit from anti-IL-13 treatment.

In the article by PIPER et al. [20] in this issue of the European Respiratory Journal, patients with poorly controlled asthma who were receiving high doses of inhaled glucocorticoids with or without other drugs for asthma were administered a humanised monoclonal antibody directed against IL-13 (tralokinumab) or placebo. The primary end-point of the study, the 6-item Asthma Control Questionnaire, was not significantly improved by active treatment. However, forced expiratory volume in $1 \mathrm{~s}$ (FEV1) and supplemental $\beta$-agonist use were both significantly improved in 
patients receiving tralokinumab. A post hoc analysis of patients with elevated sputum IL-13 $\left(>10 \mathrm{pg} \cdot \mathrm{mL}^{-1}\right)$ at study entry had numerically higher improvements in FEV1 compared with subjects whose values were lower than these thresholds, suggesting that the presence of residual IL-13 was associated with a larger FEV1 response. However, the numbers of patients in this subgroup were too small to conduct an adequate statistical analysis.

These data bear much in common with recently published findings from a trial of lebrikizumab, another anti-IL-13 monoclonal antibody, in patients with asthma [21]. The treatment group who received lebrikizumab had a significant mean improvement in FEV1, 5.5\% higher than that in patients receiving placebo. As part of the analysis, patients were identified at the onset of the trial as having serum periostin concentrations that were either higher or lower than the group median. Those with high serum periostin concentrations demonstrated larger improvements in FEV1 during treatment with lebrikizumab, while those with lower levels of periostin had FEV1 values that were not significantly different from placebo. Measurement of exhaled nitric oxide served a similar discriminatory function, as a post hoc analysis revealed that patients with values above the group median had larger improvements in FEV1 while receiving lebrikizumab than patients with lower levels.

These data from the trial of tralokinumab are encouraging and bring clinical investigators one step closer to the use of anti-IL13 antibodies in patients with refractory asthma. Larger trials are eagerly awaited, both to confirm these initial findings as well as to explore what effects these drugs may have upon asthma exacerbations and patient-reported outcomes. Studies of both tralokinumab and lebrikizumab do suggest that IL-13 inhibition may be most effective in patients who have evidence of residual IL-13 activity with persistent Th2 inflammation. Determination of which diagnostic tests will be most costeffective for assessing phenotypic status will hopefully be born out in the ensuing phase III studies of these agents.

\section{STATEMENT OF INTEREST}

A statement of interest for J. Corren can be found at www.erj. ersjournals.com/site/misc/statements.xhtml

\section{REFERENCES}

1 Minty A, Chalon P, Derocq JM, et al. Interleukin-13 is a new human lymphokine regulating inflammatory and immune responses. Nature 1993; 362: 248-250.

2 Punnonen J, Aversa G, Cocks BG, et al. Interleukin 13 induces interleukin 4-independent IgG4 and IgE synthesis and CD23 expression by human B cells. Proc Natl Acad Sci USA 1993; 90: 3730-3734.

3 Horie S, Okubo Y, Hossain M, et al. Interleukin-13 but not interleukin-4 prolongs eosinophil survival and induces eosinophil chemotaxis. Intern Med 1997; 36: 179-185.

4 Luttmann W, Knoechel B, Foerster M, et al. Activation of human eosinophils by IL-13. Induction of CD69 surface antigen, its relationship to messenger RNA expression, and promotion of cellular viability. J Immunol 1996; 157: 1678-1683.

5 Kaur D, Hollins F, Woodman L, et al. Mast cells express IL-13R $\alpha 1$ : IL-13 promotes human lung mast cell proliferation and FceRI expression. Allergy 2006; 61: 1047-1053.

6 Ahdieh M, Vandenbos T, Youakim A. Lung epithelial barrier function and wound healing are decreased by IL-4 and IL-13 and enhanced by IFN- $\gamma$. Am J Physiol Cell Physiol 2001; 281: C2029C2038.

7 Kondo M, Tamaoki J, Takeyama K, et al. Elimination of IL-13 reverses established goblet cell metaplasia into ciliated epithelia in airway epithelial cell culture. Allergol Int 2006; 55: 329-336.

8 Richter A, Puddicombe SM, Lordan JL, et al. The contribution of interleukin (IL)-4 and IL-13 to the epithelial-mesenchymal trophic unit in asthma. Am J Respir Cell Mol Biol 2001; 25: 385-391.

9 Laporte JC, Moore PE, Baraldo S, et al. Direct effects of interleukin13 on signaling pathways for physiological responses in cultured human airway smooth muscle cells. Am J Respir Crit Care Med 2001; 164: 141-148.

10 Grunstein MM, Hakonarson H, Leiter J, et al. IL-13-dependent autocrine signaling mediates altered responsiveness of IgEsensitized airway smooth muscle. Am J Physiol Lung Cell Mol Physiol 2002; 282: L520-L528.

11 Grunig G, Warnock M, Wakil AE, et al. Requirement for IL-13 independently of IL-4 in experimental asthma. Science 1998; 282: 2261-2263.

12 Wills-Karp M, Luyimbazi J, Xu X, et al. Interleukin-13: central mediator of allergic asthma. Science 1998; 282: 2258-2261.

13 Wong CK, Ho CY, Ko FW, et al. Proinflammatory cytokines (IL-17, IL-6, IL-18 and IL-12) and Th cytokines (IFN- $\gamma$, IL-4, IL-10 and IL13) in patients with allergic asthma. Clin Exp Immunol 2001; 125: 177-183.

14 Berry MA, Parker D, Neale N, et al. Sputum and bronchial submucosal IL-13 expression in asthma and eosinophilic bronchitis. J Allergy Clin Immunol 2004; 114: 1106-1109.

15 Prieto J, Lensmar C, Roquet A, et al. Increased interleukin-13 mRNA expression in bronchoalveolar lavage cells of atopic patients with mild asthma after repeated low-dose allergen provocations. Respir Med 2000; 94: 806-814.

16 Munitz A, Brandt EB, Mingler M, et al. Distinct roles for IL-13 and IL-4 via IL-13 receptor $\alpha 1$ and the type II IL-4 receptor in asthma pathogenesis. Proc Natl Acad Sci USA 2008; 105: 7240-7245.

17 Kotsimbos TC, Ernst P, Hamid QA. Interleukin-13 and interleukin-4 are coexpressed in atopic asthma. Proc Assoc Am Physicians 1996; 108: 368-373.

18 Woodruff PG, Modrek B, Choy DF, et al. T-helper type 2-driven inflammation defines major subphenotypes of asthma. Am J Respir Crit Care Med 2009; 180: 388-395.

19 Chibana K, Trudeau JB, Mustovich AT, et al. IL-13 induced increases in nitrite levels are primarily driven by increases in inducible nitric oxide synthase as compared with effects on arginases in human primary bronchial epithelial cells. Clin Exp Allergy 2008; 38: 936-946.

20 Piper E, Brightling C, Niven R, et al. A phase II placebo-controlled study of tralokinumab in moderate-to- severe asthma. Eur Respir J 2013; 41: 330-338.

21 Corren J, Lemanske RF, Hanania NA, et al. Lebrikizumab treatment in adults with asthma. N Engl J Med 2011; 365: 1088-1098. 